Lidia Maria Soares Pires Cardel ${ }^{1}$

Paulo Henrique Dantas Pita ${ }^{2}$

Lara Rosa Meirelles Barros ${ }^{3}$

Marina Ferreira de Araújo Fernandes ${ }^{4}$

Caio Araújo dos Santos ${ }^{5}$

\title{
UM BALANÇO DA UTILIZAÇÃO DAS FERRAMENTAS DE AUXÍLIO À PESQUISA QUALITATIVA (CAQDAS): TRINTA ANOS DE MST NA MÍDIA IMPRESSA (1984-2014)
}

\author{
A BALANCE OF THE USE OF TOOLS TO AID QUALITATIVE RESEARCH (CAQDAS): \\ THIRTY YEARS OF THE LANDLESS MOVEMENT IN THE PRINT MEDIA (1984-2014)
}

\section{Resumo}

A finalidade deste artigo é relatar a relevância da utilização dos CAQDAS (computer-assisted qualitative data analysis software) na coleta e na análise dos discursos da mídia impressa nacional publicados desde $o$ aparecimento do MST (Movimento dos Trabalhadores Rurais Sem Terra), em 17 de abril de 1984, até o ano de 2014, quando o movimento completou 30 anos de existência. Esse levantamento justifica-se pela importância do MST na formação de um novo cenário sobre a questão fundiária no Brasil, como tam-

1 Professora associada IV do Departamento de Sociologia da Universidade Federal da Bahia (UFBA), coordenadora do Núcleo de Estudos Ambientais e Rurais. E-mail: Icardel@ufba.br.

2 Doutorando do Programa de Pós-graduação em Sociologia da Universidade de Campinas (Unicamp), mestre em Ciências Sociais pela Universidade Federal da Bahia (UFBA) e pesquisador do Núcleo de Estudos Ambientais e Rurais (Nuclear). E-mail: paulohenrique.ba@gmail.com.

3 Mestranda do Programa de Pós-graduação de Antropologia da Universidade Federal da Bahia (UFBA). E-mail: lararosamb@gmail.com.

4 Doutoranda do Programa de Ciências Políticas da Universidade de Brasília (UnB), mestre em Ciências Sociais pela Universidade Federal da Bahia (UFBA) e pesquisadora do Núcleo de Estudos Ambientais e Rurais. E-mail: maricotafe@hotmail.com.

5 Mestrando do Programa de Pós-Graduação em Educação e Contemporaneidade da Universidade do Estado da Bahia (Uneb) e bacharel em Psicologia pela Universidade Federal da Bahia (UFBA). E-mail: caio. psicologia@hotmail.com. 
bém pela capacidade deste movimento social em influenciar o Estado Brasileiro na elaboração e produção de "políticas públicas transversais" (IVO, 2005) que impulsionaram a mitigação da pobreza no meio rural, a concepção de novas tecnologias para a agricultura familiar e a criação de novos espaços educacionais voltados para a população ligada à agricultura familiar e agroecológica. Por outro lado, visando complexificar o objetivo desta investigação, esta pesquisa também teve como meta compreender o processo de burocratização do MST a partir do momento em que este escolheu se aproximar da estrutura burocrática do Estado, elegendo suas lideranças para cargos no legislativo, como também cedendo seus quadros para governos municipais, estaduais e federais.

Palavras-chave: MST. Mídia impressa. CAQDAS. Movimentos sociais.

Abstract

The purpose of this article is to report the relevance of the use of CAQDAS (computer-aided qualitative data analysis software) in the collection and analysis of national print media discs since the appearance of the MST (Landless Workers' Movement), April 17, 1984, through the year 2014, When the movement has completed 30 years of existence. This research is justified by the importance of the MST in the formation of a new scenario on land problems in Brazil, as well as in the capacity of this social movement to influence the Brazilian State in the elaboration and production of "transversal public policies" (IVO, 2005), Which promoted rural poverty alleviation, a conception of new tools for family farming, and the creation of new educational spaces for a population linked to family and agroecological agriculture. In order to complicate the objective of this research, this research also had as its purpose the process of bureaucratization of the MST from the moment this Social Movement chose to approach the bureaucratic structure of the State, electing its leadership to positions in the legislature, as well as, Giving his paintings to municipal, state and federal governments.

Keywords: MST. Print media. CAQDAS. Social movements.

\section{INTRODUÇÃO}

Objetivamos neste artigo analisar metodologicamente quais os ganhos e as limitações da utilização dos softwares na pesquisa sociológica com recortes temporais de médio e longo alcance. Como aponta a ampla literatura sobre os processos metodológicos na área das Ciências Sociais, a codificação é um dos processos cruciais para a classificação, o ordenamento e a construção do referencial de análise em pesquisas com um vasto e complexo grupo de material coletado (big data) ${ }^{6}$. Sendo assim, no caso específico da nossa pesquisa, procu-

6 Segundo Gibbs (2009, p. 60): “a codificação é a forma como você define sobre o que se trata os dados em análise e envolve a identificação e o registro de uma ou mais passagens de texto ou outros itens dos dados, como partes do quadro geral que, em algum sentido, exemplificam a mesma ideia teórica ou descritiva". Nesse mesmo sentido, Basit (2003, p. 152) afirma em seus estudos metodológicos sobre estudos de caso etnográficos na área da Educação, nos quais utilizou técnicas de investigação e análise multivariadas, que "os softwares para codificação e busca de dados tornaram mais simples a vida do pesquisador. No primeiro projeto [sem o uso das ferramentas] a análise dos dados foi entediante e frustrante. No segundo, 
raremos relatar quais foram os ganhos e as dificuldades encontradas ao utilizarmos tais recursos na coleta e análise sobre os discursos das mídias impressas nacionais publicados desde o aparecimento do Movimento dos Trabalhadores Sem Terra (MST), em 17 de abril de 1984, até o ano de 2014, quando o movimento completou 30 anos de existência. Esse levantamento justifica-se pela importância do MST na formação de um novo cenário sobre a questão fundiária no Brasil, como também pela capacidade desse movimento social em influenciar o Estado Brasileiro na elaboração e produção de "políticas públicas transversais" (IVO, 2005) que impulsionaram a mitigação da pobreza no meio rural, a criação de novas tecnologias para a agricultura familiar e a criação de novos espaços educacionais voltados para a população ligada à agricultura familiar e agroecológica. Por outro lado, visando complexificar o objetivo da investigação proposta, a pesquisa central também tem como meta compreender o processo de burocratização ${ }^{7}$ do MST a partir do momento em que este escolheu se aproximar da estrutura burocrática do Estado, elegendo suas lideranças para cargos no legislativo, assim como cedendo seus quadros para governos municipais, estaduais e federais.

Assim sendo, com a pesquisa ainda em curso, esperamos encontrar no discurso da mídia impressa dos últimos 30 anos elementos esclarecedores para elucidar o papel do MST no cenário político nacional contemporâneo. Entretanto, em função do recorte temporal dilatado para uma investigação qualitativa de cunho sociológico, foi necessário delimitar a abrangência das mídias escritas a serem analisadas. Desse modo, por meio da democratização da produção textual e pela importância alcançada por alguns grupos editoriais em nível nacional, optamos por trabalhar com o acervo de três grandes jornais brasileiros: a Folha de São Paulo, O Globo e O Estado de S. Paulo, que já possuem todo o seu material digitalizado e disponibilizado para pesquisas dessa natureza ${ }^{8}$.

a codificação foi mais tranquila, apesar do tempo considerável investido na aprendizagem do software. O computador permitiu maior aprofundamento da análise e os relatórios gerados foram inestimáveis. De qualquer forma, a codificação foi um exercício intelectual nos dois casos. $O$ software não eliminou a necessidade de pensar e deliberar, gerar códigos e rejeitar ou substituí-los quando necessário".

7 No sentido weberiano (WEBER, 1991), em que o processo de burocratização está intimamente ligado ao processo da dominação legítima.

8 É importante ressaltar que o uso de dados veiculados pela mídia impressa vem sendo utilizados pelos pesquisadores da área das Ciências Sociais há algumas décadas. (BARRANCO; WISLER, 1999; FRANZOSI; 1987; MUELLER, 1997; MYERS; CANIGLIA, 2004; OLIVER; MANEY, 2000) Especificamente no Brasil, podemos incluir outros autores que realizaram pesquisas na mesma temática (Movimentos dos Trabalhadores Sem Terra e mídia), mas que se pautaram por metodologias qualitativas e quantitativas sem o uso de softwares. Entre eles, Bruno Konder Comparato (2001), Maria da Glória Gohn (2010) e Melo e Tatagiba (2017), para citarmos os mais recentes. O que diferenciou a nossa pesquisa e lhe conferiu uma originalidade frente às pesquisas dos autores citados foi a criação e a análise de uma extensa base de dados (big data) que exigiu, da nossa parte, a utilização dos CAQDAS e a criação do manual de códigos para a análise qualitativa sobre uma base quantitativa. Em suma, o diferencial desse trabalho 


\section{A BASE EMPÍRICA DA PESQUISA}

Diante do volume dos dados coletados até o momento, apenas no jornal O Estado de S. Paulo9 e na busca por operacionalizar metodologicamente o objeto pesquisado, optamos pela utilização dos softwares de apoio a análise de dados qualitativos (CAQDAS: computer-assisted qualitative data analysis software) e quantitativos. Assim, após a análise amostral da primeira coleta de dados ${ }^{10}$ reunidos por meio do software $\mathrm{R}$, passamos a utilizar o software Atlas.ti, para a análise qualitativa dos dados textuais, imagéticos e audiovisuais, e o software Sphinx, para a construção de um questionário digital que aglutinou quantitativamente os dados da mesma temática, possibilitando a criação de tabelas e gráficos, o cruzamento de variáveis e a elaboração de análises estatísticas ${ }^{11}$. Para tanto, construímos um manual de códigos por meio da leitura prévia de 10\% do total de 8.264 arquivos com uma ou mais matérias recolhidas no acervo do jornal O Estado de S. Paulo entre os anos de 1980 (momento que antecede a criação do MST, em 1984, mas que já nos apontava a reorganização da luta pela terra) à 2014 , totalizando 834 matérias lidas, debatidas e codificadas à luz da teoria sociológica e do arcabouço epistemológico da Sociologia Rural, da Sociologia das Mídias e dos estudos sobre os movimentos sociais para a elaboração das palavras-chave.

está na criação de uma metodologia interdisciplinar que visa dar suporte às pesquisas sociológicas que pretendem trabalhar com grande quantidade de dados e com um extenso recorte temporal no campo das Ciências Sociais.

9 A base de dados do estado de São Paulo possui 8.264 arquivos em PDF e cada arquivo possui de duas a três matérias sobre a temática estudada. Esses arquivos foram inicialmente coletados em formato JPEG e convertidos para PDF com caracteres reconhecidos por meio do software ABBYY.

10 Para analisar todo o material coletado, utilizamos a técnica de análise de discurso/conteúdo que nos facultou a condição da análise objetiva e subjetiva dos dados. Essas técnicas transversalizadas de utilização de softwares e análise de discurso/conteúdo nos deu a condição de termos acesso ao contexto imediato da enunciação e, no sentido mais amplo, os requisitos para compreender a dimensão e o contexto sócio-histórico e ideológico do objeto estudado.

11 Para explanar as etapas de utilização dos softwares é importante demonstrar o desenho metodológico que elaboramos para nossa pesquisa: 1) coleta de dados em acervos digitais por meio de script e software $\mathrm{R}$; 2) formatação da base de dados; 3) elaboração de amostragens aleatórias (divisão em decênios); 4) elaboração de novas amostragens aleatórias dentro dos decênios; 5) levantamento de palavras-chave de matérias em cada decênio; 6) equalização das palavras-chave em categorias para a estruturação do questionário digital, no Sphinx, e dos códigos, no Atlas.ti.; 7) criação de um manual de preenchimento e operacionalização das categorias elaboradas.; 8) aplicação de questionários e codificação das matérias visando a relação com os eixos de análise. 
Gráfico 1 - Comparativo de arquivos selecionados versus arquivos totais

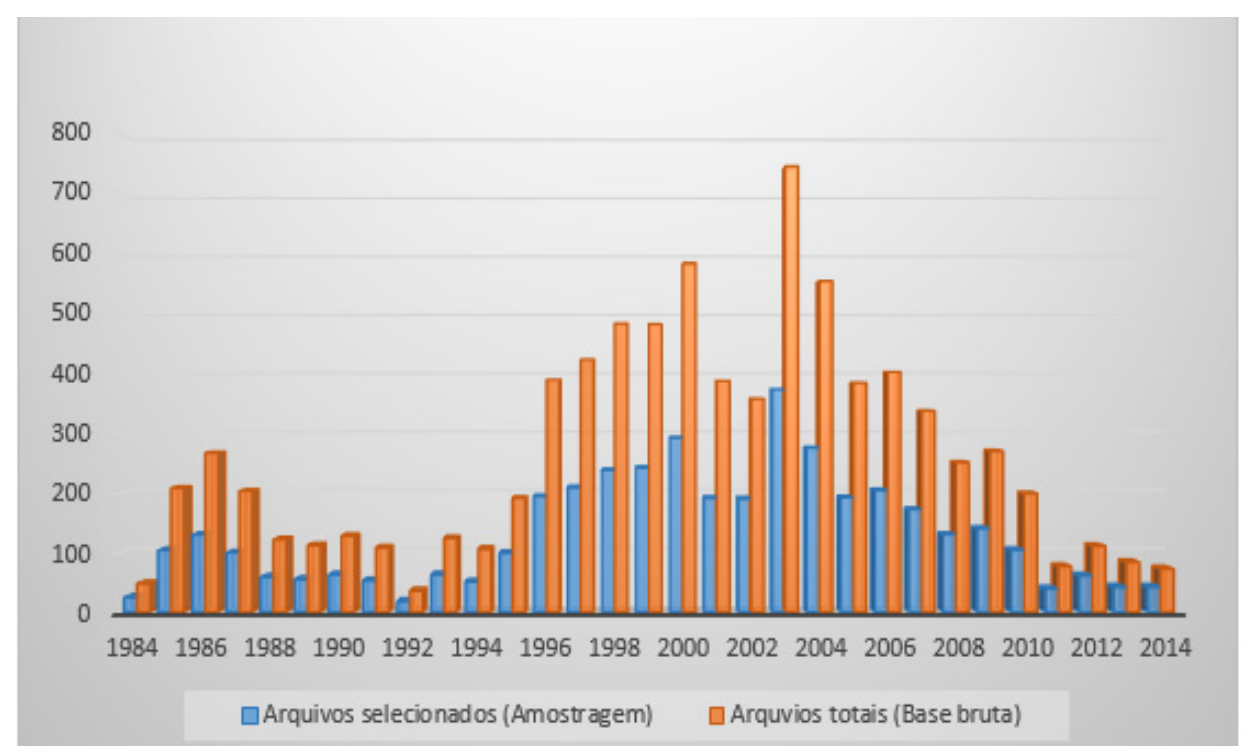

Fonte: Elaborado pelo autor.

Assim, visualiza-se por meio deste gráfico que o recorte amostral possível para a nossa pesquisa, mesmo utilizando softwares com grande capacidade de abrangência analítica, não supera mais da metade do total dos arquivos coletados pelo script R. ${ }^{12}$ Isso ocorre em função das limitações impostas pela temática e pelo recorte temporal da pesquisa, pois, ao nos propormos a investigar toda a produção textual de uma mídia escrita num período de 30 anos, nos deparamos com uma extensão de dados que, se fossem trabalhados in totum, consumiriam um tempo inexequível de organização do material.

Nesse sentido, a qualidade e a abrangência desses softwares nos indicaram a possibilidade da criação de modelos conceituais e redes de informações sobre a trajetória do MST entre 1984 a 2014, evidenciando a conexão entre os dados, além de oferecerem recursos para a geração dos relatórios e a visualização dos resultados. Obviamente, todo pesquisador que utiliza essas ferramentas deve ter a consciência epistemológica de que nenhum desses softwares estabelece os caminhos a serem seguidos pelo processo investigativo, assim como não são ferramentas epistemológicas sobre como analisar os dados ou como inter-

12 Versão utilizada: RIPLEY, et. al. (2013) 
pretar a codificação. Essas tarefas são de responsabilidade do pesquisador, que deve estar munido de um aparato teórico sólido sobre o tema pesquisado.

Ainda que se questione o quão legítimo, em termos científicos, seja a utilização dos CAQDAS nas pesquisas em Ciências Sociais, negar o quão facilitadores são, no que tange ao tratamento dos dados, denota uma falta de aproximação e contato com a guinada digital que as Ciências Humanas vêm tomando. Por intermédio dos softwares, passa-se a ter recursos sumamente importantes para o pesquisador, pois, além da possibilidade de se armazenar e agrupar uma quantidade elevada de informações acerca do objeto investigado, ainda é possível a extração de seus resultados e o cruzamento das informações obtidas. Nessa pesquisa, o problema central com o qual nos deparamos no processo da coleta dos dados foi como equalizar os percalços e as oportunidades a fim de criar um método de fato eficiente e válido para trabalharmos com uma realidade de dados bastante extensa. $O$ desafio não está posto necessariamente no "tamanho dos dados", mas na complexidade que se expande quando pensamos em minimizar os possíveis erros metodológicos durante o processo.

No caso da nossa pesquisa, esbarramos na extensão temporal da temática estudada. Propomo-nos, no início, a trabalhar os 30 anos da história do MST de forma monolítica. Entretanto, o tempo histórico e político brasileiro entre o período de 1984 a 2014 apresentou mudanças e rupturas sociais, econômicas e culturais profundas, e os nossos dados refletiam essas complexidades. Após nos vermos impedidos empiricamente de criar categorias totalizantes dos trinta anos da história do MST, decidimos dividir a base de dados em três decênios (1984-1994; 1995-2005; 2006-2014). Essa proposta seguiu o critério das mudanças sociopolíticas presentes na história recente do país, como a abertura política iniciada em 1984 (a partir do movimento das Diretas Já); as eleições presidenciais de Fernando Henrique Cardoso (1994-2012), de Luís Inácio Lula da Silva (2003-2011) e de Dilma Rousseff (2012-2016); assim como o apogeu da visibilidade dos movimentos sociais por meio de políticas públicas restitutivas e redistributivas (FRASER; HONNETH, 2006)

Dessa forma, mediante o exposto acima, constatamos que uma pesquisa que vise como resultado um trabalho metodologicamente confiável e com relevância científica precisa problematizar o método previamente com equidade, a fim de dar conta antecipadamente da maioria dos problemas que poderão se tornar presentes em seu estudo. Essa etapa é o que chamaremos de fase exploratória, onde o tema a ser pesquisado possui uma amplitude que deverá ser remodelada epistemologicamente pelos conceitos teóricos e metodológicos do campo científico escolhido. É importante que o pesquisador visualize 
esse momento com uma sensatez que o distancie do senso comum erudito, ${ }^{13}$ pelo fato desse momento singular de construção do modelo e do estado da arte se tonar, posteriormente, a base de todas as diretrizes que serão tomadas dali para frente.

Nesse momento, é imprescindível que se tenha noção da realidade dos dados que serão processados, assim como do tipo de análise qualitativa que será feita, uma vez que o tipo de investigação interfere na ferramenta a ser utilizada. ${ }^{14}$ Para Lage (2011), a seleção dos CAQDAS deve estar diretamente relacionada à abordagem metodológica eleita pelo pesquisador, considerando que todo software de análise qualitativa é elaborado sob um tipo de metodologia específico proposto pelo seu desenvolvedor. Todavia, na prática, outros fatores precisam ser levados em consideração. No caso da pesquisa que estamos elaborando, os dados brutos coletados mostraram-se inoperantes em uma primeira abordagem. Quando começamos a lançar mão do conhecimento sociológico adequado, qual seja, das ferramentas epistemológicas da Sociologia das Mídias, da Sociologia Rural e dos Movimentos Sociais, moldamos o método a ser utilizado para depurar o material coletado. Assim, os links e os insights começaram a dar forma e esteio ao tratamento dos dados. Foi só após superarmos essas dificuldades que a pesquisa começou a apresentar os primeiros resultados.

Em termos práticos, foi necessário adequar (para além da metodologia, pensando também em quesitos operacionais ligados a informática) os dados à plataforma de análise que usamos em relação ao tipo de documento, tamanho, forma de armazenamento e recursos analíticos disponíveis. Entre um software e outro, por mais que se busque cumprir com o mesmo tipo de análise, há uma diferença considerável no que diz respeito a seus recursos e possibilidades. Aqui entra a perspectiva do recorte empírico da pesquisa e a escolha do arcabouço teórico e epistemológico.

Lewins e Silver (2009) recomendam que o pesquisador responda a um conjunto de questões antes de partir para a escolha de seu CAQDAS. De forma resumida, algumas delas são: qual o tipo e volume de dados de sua pesquisa? Qual é a sua abordagem teórica para o tratamento dos dados? Qual é o tipo de questionamento ou consultas que precisará fazer aos dados? Será necessário usar algum processo de codificação? Em caso afirmativo, quais as suas características? Será preciso trabalhar com temas e/ou categorias de informações? A

3 Como aponta Bourdieu (2002).

14 A preocupação com a possibilidade de apagões sistemáticos nos aplicativos e o receio de perder repentinamente meses e até anos de pesquisa pela contingência do programa "travar" por meio de bugs e crash geram dúvidas pertinentes sobre a confiabilidade dos CAQDAS na área de pesquisas qualitativas. 
pesquisa é executada em grupo? Em síntese, prepara-se um terreno fértil para a adoção das técnicas mais propícias a cada contexto; essa é tarefa intransferível do pesquisador.

Superada a definição da ferramenta, todos os olhares direcionam-se à amostra, tendo ela total importância entre a fase exploratória e o início do estado da arte sobre a temática explorada. Ao considerar a amostra o principal objeto deste trabalho, idealmente, a ferramenta precisa se adequar a ela e não o contrário. No nosso caso, enfrentamos dificuldades quanto a isso por conta de alguns fatores. $O$ primeiro foi devido ao tamanho elevado do nosso universo de matérias. Ao propor trabalhar com trinta anos de veiculações nos jornais O Estado de S. Paulo, Folha de S.Paulo e O Globo sobre todos os assuntos veiculados relativos ao MST, não tínhamos o completo conhecimento de que o processo de coleta nos renderia alguns milhares de matérias pela frente. Com isso, enfrentamos alguns percalços inesperados devido a nossa tamanha despretensão da complexidade de alguns quesitos, por exemplo, o armazenamento dos dados. Para que todos os pesquisadores do projeto pudessem manipulá-los conjuntamente foi necessário depositá-los em nuvem, utilizando um servidor especializado em armazenagem de big data.

Outro entrave que surgiu diz respeito à codificação. Possuímos um sujeito a analisar (o MST) que muda de configuração nos discursos da mídia, ao longo dos 30 anos, de forma latente. Isso traz um desafio na codificação que é exatamente o de criar categorias que se proponham a dar conta dessas diferentes leituras a partir da reportagem e que viabilizem uma análise concisa posteriormente. $O$ desafio estabelece-se, sobretudo, no momento em que essas categorias de análise devem abarcar toda a realidade posta para que seja viável uma análise de conteúdo/discurso, ${ }^{15}$ inclusive atentando-se para que não se caia no fetichismo da codificação exacerbada, um problema comum quando se lida com uma gama de dados extensos e heterogêneos. É fundamental, nesse sentido, "considerar que os principais softwares atuais para apoio à análise de dados qualitativos foram desenhados com base na premissa de que o pesquisador precisa tanto de proximidade quanto de distância de seus dados". (RICHARDS, 1998; BAZELEY, 2007 apud LAGE; GODOY, 2008, p. 81)

Vencida a fase exploratória, constatamos que esse é o momento mais trabalhoso do estudo, sendo essa etapa muito mais laboral do que organizacio-

15 No caso dessa pesquisa, após levantarmos mais de uma centena de categorias empíricas referentes ao objeto estudado, criamos um questionário único que nos possibilitou instrumentalizar, por meio de uma análise sociológica apurada, conceitos-chave que emergiram da análise sobre a enorme complexidade social encontrada no material analisado. 
nal/analítica. É necessário frisar que todo o trabalho presente nessa fase inicial consiste na diminuição de impactos negativos que venham a emergir durante a pesquisa em si e que viabilizem um estudo posterior eficiente e rico em substrato para a análise.

Uma das técnicas mais utilizadas para superar as dificuldades da investigação de uma grande base de material é a construção de uma base amostral. No nosso caso, com o auxílio dos softwares de análise qualitativa e quantitativa, foi possível trabalhar com $50 \%$ dos dados coletados, um percentual bem acima da média utilizada, que nos trouxe ganhos analíticos sólidos e confiáveis. Com efeito, uma amostra tão alta lança luz e converge na direção de uma percepção mais apurada e, ao mesmo tempo, precisa acerca da realidade dos dados, sobretudo no momento inicial.

Assim, visando compreender a história e os processos sociológicos que envolvem a relação do MST com o Estado, essa pesquisa tem um viés inovador ao propor trazer à luz, por meio do discurso sociológico, todas as matérias já publicadas (nas mídias escritas mencionadas) sobre esse movimento social desde a sua fundação, em 1984, até o ano de 2014, quando a sua relação com o governo do Partido dos Trabalhadores tornou-se tensa em função da escolha explícita da então presidente Dilma Rousseff pela política de incentivo ao agronegócio.

Para tanto, optamos por iniciar a coleta de dados pelo jornal O Estado de S. Paulo, devido a sua complexidade em relação à temática pesquisada. Na fase exploratória, por meio de rodadas de leitura ${ }^{16}$ das amostragens das matérias, foram encontrados elementos fundamentais que justificaram a sua escolha como ponto de partida na pesquisa, a exemplo do caderno Questão Agrária, criado na década de 1980 com a finalidade de reunir, independente da região do país ou dos agentes envolvidos, todas as notícias sobre as ações relacionadas ao MST e às questões fundiárias em nível nacional.

Ao optarmos por pesquisar sociologicamente trazendo para o escopo do trabalho todas as matérias publicadas, já sabíamos de antemão, posteriormente à revisão bibliográfica, que não havia ainda nenhuma investigação dessa magnitude. Obviamente, o desafio só foi lançado por termos como ferramentas de pesquisa os programas Atlas.ti, Sphinx e R como ferramentas fundamentais para buscar, organizar e analisar o volume de matérias coletada através da busca por palavras-chave e categorias específicas; uma vez que pelo recorte temporal

16 A técnica de rodadas de leitura refere-se à fase exploratória da referida pesquisa. A base de dados foi dividida em 3 decênios e foram realizadas 5 amostragens por decênio, o que resultou em 15 rodadas de leitura. Cada rodada envolveu a leitura coletiva dos pesquisadores que levantaram as categorias, os posicionamentos discursivos, os atores e a representação social a fim de encontrar padrões da mídia impressa sobre o MST em cada decênio. 
e pela quantidade de dados seria extremamente laborioso, ou mesmo inviável, trabalhar com mais 10.000 matérias por mídia ${ }^{17}$ sem os recursos desses softwares. Obviamente, como já foi mencionado, essas ferramentas não trabalham por si e aqui entra o papel decisivo do pesquisador. Assim, por meio das leituras prévias e da criação de categorias sociológicas e de mediação, conseguimos, até o momento atual de pesquisa (após o processo de extração elaborado pelo software R e de quantificação pelo software Sphinx), trabalhar sistematicamente com um processo de codificação laborioso por meio do software Atlas.ti, como demonstramos na figura abaixo.

Figura 1 - Exemplo de aplicação de códigos teóricos e empíricos

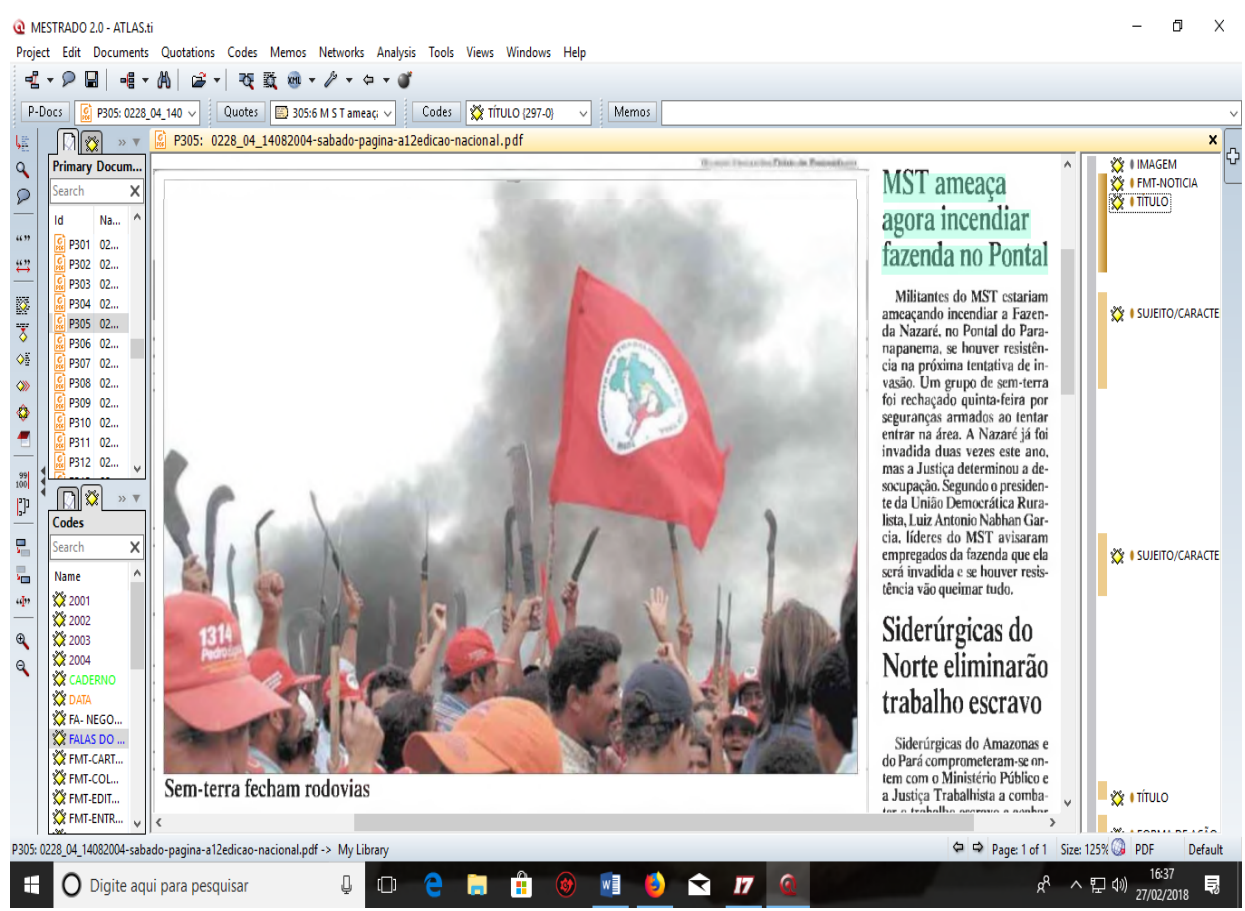

Fonte: Elaborado pelo autor.

17 A estimativa foi feita levando em conta o total de 8.264 arquivos encontrados na mídia impressa O Estado de S. Paulo. Cada arquivo possui uma ou mais matérias, assim como gráficos e imagens. 
Em suma, o que buscamos com esta pesquisa? Em um sentido amplo, ela visa dar continuidade aos estudos realizados na linha de pesquisa sobre mídia e movimentos sociais, direcionando-se para a análise da mídia impressa pela sua importância enquanto construtora de um discurso multifocal do cotidiano brasileiro. No sentido específico dos estudos sobre o MST, esperamos contribuir para a compreensão da dinâmica política interna e externa desse movimento identificando os atores sociais e os interlocutores que são chamados para falar a favor e/ou contra o movimento. Por meio dos nossos estudos será possível, inclusive, elencar mudanças de comportamento de ações e narrativas do MST ao longo dos seus 30 anos, assim como as suas transformações referentes às pautas e estratégias de ações relativas à reforma agrária e as temáticas que tangenciam as políticas públicas sobre a estrutura fundiária brasileira.

Responder essas questões e tabular todas as matérias por meio da análise de conteúdo/discurso, gráficos e nuvens de palavras ${ }^{18}$ faz parte dos aparatos metodológicos fundamentais dentro das Ciências Humanas. Na Sociologia contemporânea, os estudos sobre movimentos sociais e mídia têm permitido compreender os movimentos para além de sua atuação interna, pois a interação destes com os meios de comunicação é central para o entendimento e a consolidação das suas dinâmicas.

Segundo Penn:

A semiologia e a análise de conteúdo [e discurso] são consideradas, muitas vezes, como sendo instrumentos de análise radicalmente diversos, mas, como afirmam tanto Leiss et al. (1977), como Curan (1976), há muitas razões para uma aproximação. Os semiólogos podem incorporar os procedimentos sistemáticos de amostragem da análise de conteúdo. Isto levará, de alguma maneira, a discutir as críticas de que o enfoque produz resultados autoconfirmadores e de que não é legítimo generalizar as conclusões de uma análise semiológica para outro material. A sistematização mais aprimorada da análise, que a análise de conteúdo [e discurso] defende, pode levar também a ajudar o semiólogo a combater acusações de seletividade (por exemplo, na construção de inventários de denotação e matrizes de possíveis sintagmas). A análise resultante deverá ser mais fidedigna (replicável) e menos dependente de idiossincrasias e habilidades de determinados analistas. (PENN, 2002, p. 339)

18 As nuvens de palavras ou word cloud serão fundamentais para a análise através de recursos visuais. 
Seguindo os passos analíticos dessa autora, ressaltamos que a utilização dos softwares tem possibilitado, para essa pesquisa, a criação de modelos conceituais e redes de informações sobre a trajetória do MST nos jornais analisados, evidenciando a conexão entre os dados e oferecendo recursos para a geração de relatórios e visualização dos resultados. Por meio da análise de conteúdo e discurso, da definição de categorias que são apresentadas na narrativa da mídia impressa, e, inclusive, da utilização das técnicas de produção desse discurso, deparamo-nos com vários veiculadores sobre o objeto estudado: o sujeito formal (sem autoria); o identificado (jornalistas e articulistas); os atores sociais integrantes do movimento; os interlocutores preferenciais da mídia (aqueles atores que são recorrentes nas matérias, como empresários rurais e políticos de várias tendências partidárias). Por meio dessas técnicas de análise e investigação, também é possível identificar quais os eventos noticiados e quais aqueles que não são suficientemente analisados, como marchas, ocupações, assentamentos e congressos nacionais e regionais.

Nessa perspectiva, para recortarmos as narrativas e os dados estatísticos e imagéticos mais representativos do foco central da pesquisa, a codificação foi guiada por um questionário digital com 54 perguntas, decodificadas via o software Sphinx, em que cada matéria lida tem como produto um questionário respondido ${ }^{19}$. Esse questionário digital foi fruto de um trabalho árduo elaborado seguindo uma rotina extensa de lapidação dos dados empíricos, que consistiu nos seguintes procedimentos: tendo como base as palavras-chave da pesquisa inicial, catalogamos empiricamente - por meio de 15 rodas de leituras mensais, com 10 matérias cada, durante seis meses - 132 categorias que serviram de base para o script $\mathrm{R}$, com o qual criamos a base de dados global. Essas categorias empíricas seguiram as bases sólidas da teoria sociológica dos estudos rurais e dos movimentos sociais, que foram amadurecidas com uma vasta bibliografia referente aos dois campos de pesquisa.

Como todo discurso, a mídia impressa possui um viés hermenêutico e valorativo. Por trás da linguagem aparente utilizada, que é propagada como neutra e objetiva, existe um ou vários grupos, classes e frações de classe que se posicionam e defendem seus pontos de vista e interesses sociais, econômicos e culturais. Na linguagem simbólica e polissêmica da mídia (e de todas as formas de linguagem), esconde-se um sentido que convém desvendar. Assim, os

19 A base de dados dessa pesquisa está sendo foco de duas dissertações de mestrado, realizadas no Programa de Pós-Graduação em Ciências Sociais da Universidade Federal da Bahia (UFBA), e de três trabalhos com bolsistas PIBIC, sendo que, em 2017, recebeu o prêmio de melhor pesquisa desenvolvida com alunos de Iniciação Científica da Área de Ciências Humanas da UFBA. 
métodos de análise de conteúdo e de discurso possibilitam uma leitura profun$\mathrm{da}^{20}$ das comunicações, indo além da leitura aparente.

Com relação à análise quantitativa, o que serve de referencial é a frequência com que surgem certas características do conteúdo. Através do questionário digital feito no software Sphinx, é possível tabular questões multifatoriais (políticas, sociais, econômicas, históricas, entre outras) sobre o MST, quantificando informações desde a sua gênese até o ano de 2014. É justamente a presença ou ausência de uma informação, característica de conteúdo ou de um conjunto de aspectos num determinado fragmento da mensagem que levamos em consideração na nossa pesquisa.

\section{ANÁLISE CRÍTICA E TEÓRICA}

A utilização da tecnologia vem acompanhando o processo histórico de desenvolvimento das pesquisas em Ciências Sociais. Alguns desses instrumentos impactaram de maneira profunda as metodologias e as formas de fazer pesquisa, como as máquinas de escrever, os gravadores, as máquinas fotográficas e, mais recentemente, os aparelhos celulares, os computadores e a internet. Uma grande parcela dessas ferramentas proporcionou mudanças operacionais nas pesquisas em Sociologia, Antropologia e Ciências Políticas; já outras foram incorporadas aos processos metodológicos e fizeram emergir novos campos de pesquisa como no caso das etnografias visuais e audiovisuais. (LAGE, 2011)

Uma importante metodologia de pesquisa que impactou os estudos sociais e se consolidou como um excelente instrumento de coleta de dados foi o questionário ou survey. $\mathrm{O}$ uso de pesquisa survey em Ciências Sociais remonta a autores clássicos como Marx, Weber e Durkheim (BABBIE, 1999) que lançaram mão de dados qualitativos e quantitativos, estabelecendo o campo de pesquisa das Ciências Sociais. A utilização dessa técnica passou por percursos diversos, mas se consolidou como um instrumento importante de pesquisa nas várias correntes de estudos sociais norte-americanos, como na Escola Sociológica de Chicago do início do século XX. Os estudos sobre a intenção de voto, a pesquisa de opinião e as correntes migratórias foram as linhas de pesquisas que inicialmente construíram os maiores vetores de desenvolvimento dos surveys. (BABBIE, 1999; SIMÕES; PEREIRA, 2007)

20 Os programas de computadores permitem uma análise mais detalhada dos textos no que diz respeito a sua mensuração, ou seja, à frequência de uma determinada unidade de análise. Assim, técnicas estatísticas avançadas puderam ser aplicadas. (BARDIN, 2009) 
A tabulação dos dados criados por meio dos surveys pode ser organizada de variadas formas. Até os anos 1990, utilizava-se cartões de papel em que eram feitas marcações de controle para posterior quantificação. Recentemente, alguns softwares considerados simples e de uso comum estão sendo utilizados com essa finalidade, como o Excel. Outro software utilizado é o SPSS, que demanda alguns conhecimentos específicos, mas opera por uma lógica próxima à do Excel. Uma variedade de outros softwares, mais específicos para pesquisa com questionários, tem alcançado visibilidade nos últimos 20 anos e um deles é o Sphinx. Esse programa foi o escolhido no desenho dessa investigação e permite ao pesquisador um entrosamento dos vários processos que envolvem a pesquisa survey, desde a construção do questionário e a coleta de respostas, passando pela tabulação e englobando alguns testes estatísticos. (BARDIN, 2009) No entanto, a utilização do Sphinx contempla uma parte restrita da pesquisa, centrando-se especificamente nos dados quantitativos. Como nossa pesquisa possui o duplo caráter quali e quanti (como já expusemos acima), utilizamos, em associação a esse software, outra ferramenta de auxílio à pesquisa, voltada para a análise qualitativa: o Atlas.ti.

O software Atlas.ti é considerado um instrumento computacional, sendo uma ferramenta que apoia análise de dados qualitativos em pesquisas acadêmicas. A utilização desse tipo de instrumento, de auxílio a análises em investigações científicas, vem crescendo desde os anos 1980. São variadas as funcionalidades desses instrumentos, mas a maioria deles opera pela organização, pelo armazenamento e pela indexação de dados, o que pode facilitar algumas análises (LAGE; GODOY, 2008), principalmente em casos de pesquisas que envolvem big data. ${ }^{21}$

O uso de CAQDAS nas práticas científicas das Ciências Sociais é recente no Brasil, mas tem alcançado importante projeção. Alguns programas de pósgraduação brasileiros, como o Centro de Pesquisas Quantitativas em Ciências Sociais da Universidade Federal de Minas Gerais, ${ }^{22}$ oferecem treinamento para utilização de metodologias quantitativas com auxílio de softwares. No curso de Ciências Sociais da Universidade Federal da Bahia (UFBA), onde o nosso núcleo de pesquisa está alocado, ${ }^{23}$ a utilização desses softwares tem uma emergência

21 Big data é o termo utilizado pera designar grande dados oriundos de fontes informacionais, como rastros digitais, metadados ou dados de armazenamento automático. Para mais informações sobre big data e seus impactos nas Ciências Sociais ver Nascimento (2015) e Lupton (2015).

22 Maiores informações em: www.fafich.ufmg.br/cpeqs e www.fafich.ufmg.br/mq.

23 Núcleo de Estudos Ambientais e Rurais (Nuclear), certificado pelo CNPq desde 1999. 
muito atual, sendo o aprendizado ainda restrito a alguns grupos de pesquisa de pós-graduação e a poucas disciplinas na graduação.

O Atlas.ti $\mathrm{t}^{24}$ é uma das ferramentas mais completas de auxílio à pesquisa qualitativa. Com o seu uso podemos armazenar grandes volume de dados, codificar uma variedade de arquivos de textos e imagens, e organizar essas codificações de forma a entender relações e contextos - essas são algumas das ferramentas que mais utilizamos nesta pesquisa. Dentre as ferramentas computacionais de uso nas Ciências Sociais, muitas não possuem sistemas de desenvolvimento aberto ou compartilhado; ${ }^{25}$ assim, são pontos negativos na escolha dessas ferramentas a restrição financeira para aquisição de licença e treinamento, e o desconhecimento dos parâmetros de desenvolvimento dos programas. Um software que se destaca pela abertura do código-fonte para desenvolvimento e que tem sido utilizado em pesquisas na área de Ciências Humanas é o R. Esse programa, que opera através de lógica de programação, permite o download em massa de diferentes arquivos da internet, assim como o trabalho com metadados e análises de rede. (NASCIMENTO, 2016)

Mediante o exposto, constatamos que a pesquisa sobre os trinta anos do MST no jornal O Estado de S. Paulo desfrutou de uma trajetória própria, intimamente guiada pela complexidade do objeto em questão. A utilização de ferramentas CAQDAS, com isso, representou não somente um auxílio relevante no que diz respeito à análise qualitativa de uma base de dados referentes aos 30 anos do MST, mas também foi introduzida por nós de forma a se adaptar às demandas do objeto em si. Assim, nossa imaginação sociológica permitiu encontrar a metodologia adequada para a apreensão da questão prévia sobre o processo de burocratização no Movimento dos Sem Terra.

Após intensos debates e revisão bibliográfica, a estrutura do estudo inicial da base de dados foi pautada por elementos descritivos e analíticos. Os dados referentes a data, formato, título e caderno das matérias foram os primeiros a serem identificados. Logo em seguida, a parte analítica deu o tom da

24 O uso de ferramentas computacionais para auxílio em pesquisa qualitativa é de grande valia para determinados desenhos de investigação científica, como no caso da análise com mídia digital, que envolve grande volume de dados. No entanto, a utilização de software dá mais apoio a algumas metodologias do que a outras, como as ferramentas do Atlas.ti, que permitem uma imersão inicial nos dados brutos e podem ser utilizadas como importante suporte a pesquisas embasadas na teoria fundamentada em dados empíricos. (STRAUSS; CORBIN, 2008)

25 "Software livre, segundo a definição criada pela Free Software Foundation, é qualquer programa de computador que pode ser usado, copiado, estudado, modificado e redistribuído com algumas restrições. A liberdade de tais diretrizes é central ao conceito, o qual se opõe ao conceito de software proprietário, mas não ao software que é vendido almejando lucro (software comercial). A maneira usual de distribuição de software livre é anexar a este uma licença de software livre e tornar o código fonte do programa disponível". Disponível em: http://www.softwarelivre.gov.br. Acesso em: 12 fev. 2017. 
pesquisa. O mapeamento dos conflitos; a identificação do sujeito em questão; a dinâmica de interação do Estado com o movimento social; as narrativas; os vínculos identitários; os compromissos coletivos do MST e a tipologia de protesto e repertórios de interação apresentaram-nos a necessidade de pesquisar o movimento de acordo com o desenrolar de sua história, repleta de eventos com afinidades eletivas próprias.

A vigilância epistemológica permitiu que inseríssemos esta pesquisa em outra dinâmica de funcionamento. Ao analisarmos as matérias das amostragens de 1984 a 2014, percebemos que a própria natureza do objeto nos exigia outra metodologia. O MST apresentava-se de forma distinta a cada decênio do seu surgimento, o que nos levou a criar a organização da base de dados seguindo os eventos históricos da realidade brasileira, como citado acima. Assim, num momento estafante da pesquisa, quando observamos que andávamos em círculos, tivemos o insight de separar a base de dados em três decênios (1984-1994, 1995-2004 e 2005-2014), cada uma com dez amostragens compostas por 15 reportagens, que foram lidas, categorizadas e serviram de ponto de partida para a construção das categorias analíticas que subsidiaram a elaboração das nuvens de conteúdo (tag clouds) apresentadas abaixo. ${ }^{26}$

A divisão em três decênios efetivou-se a partir das informações observadas em cada período: a abertura política brasileira no primeiro decênio; o início da redemocratização brasileira por meio de eleições diretas no segundo decênio; a ascensão dos Partidos dos Trabalhadores no terceiro decênio. Observamos que a narrativa sobre o MST se transfigurava e se apresentava de forma distinta a cada decênio, o que abriu um amplo leque de possibilidades de análise.

A primeira década revelou, em primeiro lugar, o sujeito sem-terra como elemento central da dinâmica da política fundiária brasileira. Categorias como "sem-terra", "colonos", "boia-fria" e "trabalhador rural" surgiam nas matérias de 1984 a 1994, delineando o sujeito a ser trabalhado. Nesse decênio, a relação do MST com o Estado é dada quase exclusivamente pela via do conflito e prevalecem nos discursos coletados sobre essa relação as categorias como "invasão", "violência jurídica" e "conflito", assim como a enorme quantidade de confrontos entre ambos.

26 Foram utilizadas 15 matérias das amostragens de cada decênio, as quais foram rodadas em um programa de reconhecimento de caracteres em que somente as partes referentes à pesquisa foram selecionadas. Depois as matérias foram rodadas no Atlas.ti para que fosse gerada a frequência de palavras, dando subsídio às nuvens obtidas pelo programa $\mathrm{R}$. 
Sendo assim, no primeiro decênio, o repertório de interação e as tipologias de protesto tornam-se evidentes, sobretudo pela via da ação direta. As categorias empíricas "tática de guerrilha", "tática de ocupações" e "conflito armado" apareceram de forma recorrente no discurso da mídia impressa para descrever as ações dos movimentos sociais. E, nesse sentido, a narrativa do MST, seus vínculos de identidade e compromissos coletivos emergiam a partir da compreensão da função social da terra, um princípio ideológico fundador do movimento e que tem como parâmetro as oposições "propriedade" x "posse" e "terras improdutivas" $\mathrm{x}$ "desapropriação", categorias êmicas que deram norte aos sujeitos do MST na década de 1980.

Figura 2 - Nuvem de palavras referente ao primeiro decênio (1984-1994)

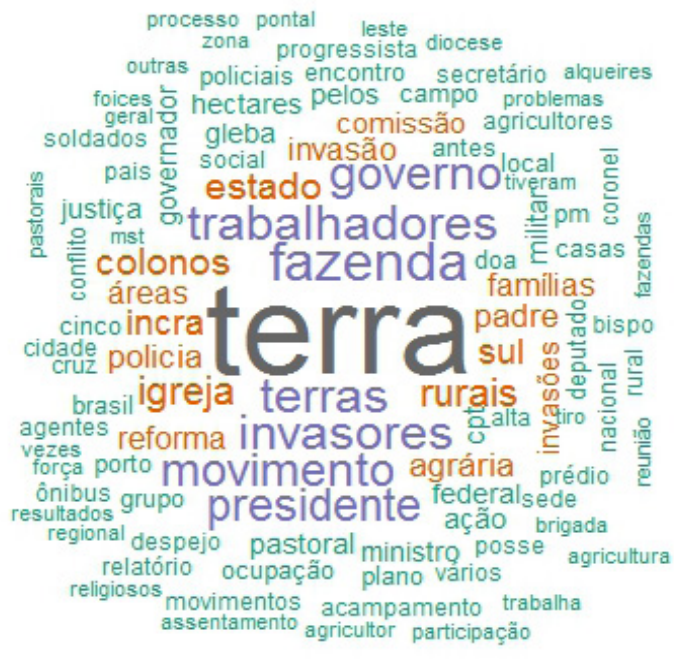

Fonte: Elaborado pelo autor no software Sphinx.

O segundo decênio, por sua vez, apresentou-se a partir de algumas ambiguidades. Se, por um lado, a política do conflito porta-se como regente da narrativa e ação do MST, por outro, as primeiras experiências de interação e integração com a arena estatal trariam à tona novos elementos de análise. Esse é o momento histórico em que o jornal O Estado de S. Paulo apresenta o sujeito sem-terra através de seu agente de mediação, ou seja, o sujeito na luta pela terra não era mais o camponês, mas o movimento social. 
Figura 3 - Nuvem de palavras referente ao segundo decênio (1994-2004)

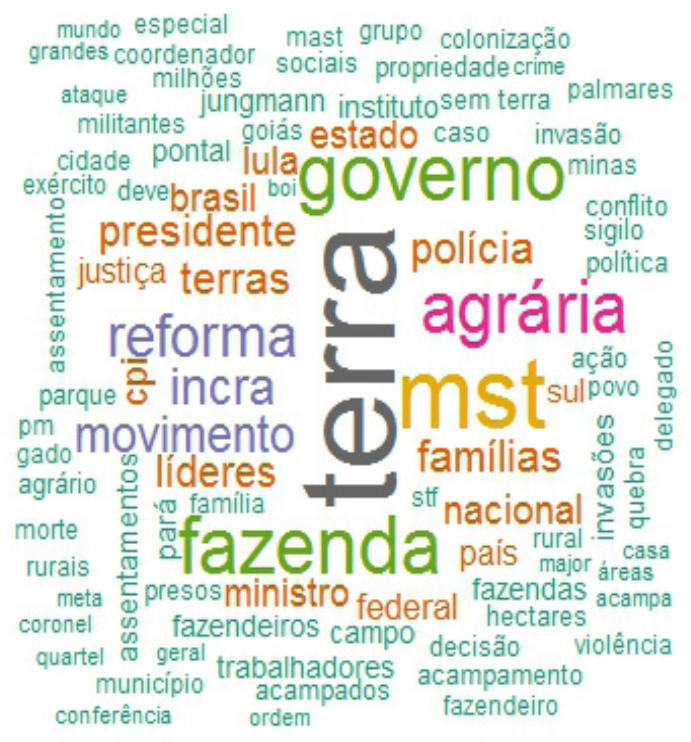

Fonte: Elaborado pelo autor no software Sphinx.

No terceiro decênio, as primeiras experiências das administrações petistas inseriram novas categorias de análise à pesquisa e, na década de 1990, assistiu-se à coexistência de termos como "aliança" e "conflito". Ainda que em estados como o Rio Grande do Sul, através da eleição do governador Olívio Dutra, em 1998, tenha havido maior aproximação entre o MST e a arena do Estado, a década de 1990 foi marcada por categorias como "radicalização" e "ausência de interlocução", no que diz respeito à esfera federal. Nesse período, os dados analisados revelaram uma mudança em relação ao sujeito protagonista da luta pela terra. Se, de 1994 a 2004, o MST apresentou-se como o mediador central das lutas camponesas, nas matérias coletadas e analisadas referentes ao decênio 2004-2014 constatamos que o sujeito "sem-terra" aparece como um coadjuvante do Movimento dos Trabalhadores Rurais Sem Terra. Confundia-se, assim, no discurso midiático e no discurso dos mediadores, o sujeito e o movimento. 
Figura 4 - Nuvem de palavras referente ao terceiro decênio (2004-2014)

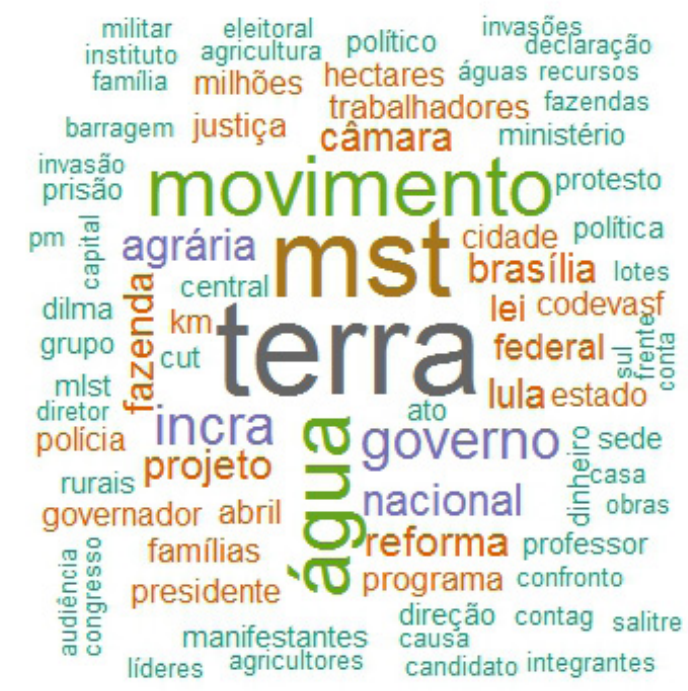

Fonte: Elaborado pelo autor no software Sphinx.

Nas três nuvens de palavras apresentadas acima, a "terra" aparece sempre como a categoria central de alocução dos vários atores inseridos nas disputas fundiárias. Entretanto, a terceira nuvem traz um conjunto de palavras onde o sistema de governabilidade se introduz no discurso dos atores sociais que compõem o MST. O repertório de interação e a tipologia de protesto são visivelmente marcadas pelo processo de burocratização do movimento, por um lado, e, por outro, pelas rupturas internas e expurgos de lideranças que insistiram no processo de "radicalização". De forma ambígua, as estratégias da "invasão como principal forma de luta", assim como os discursos sobre "negociação", "apoio" e "participação no governo", fizeram parte tanto do discurso da mídia impressa como das lideranças do MST. Nesse sentido, os compromissos coletivos do movimento também comportaram uma conjunção de elementos que se tensionaram entre si: estiveram presentes a luta pela "função social da terra", os discursos do movimento sobre o "balanço da reforma agrária", assim como a participação política no interior do governo para auxiliar a "construção de políticas públicas". Como demonstra a pesquisa de Melo e Tatagiba: 
Podemos perceber que o Movimento dos Trabalhadores Sem-terra (MST) é o principal responsável pela queda de sua base [do gráfico sobre a história das mobilizações entre 2003 a 2010]. Essa organização é a que apresenta maior concentração de protestos em 2003, 25\% deles, e em 2010 ela já se encontra no patamar das demais, por volta de $5 \%$. A Central Única de Trabalhadores (CUT) apresenta dois picos de protesto, os anos de 2007 e 2009, no mais segue quase que uma constante. Já a União Nacional dos Estudantes (UNE) varia pouco. O gráfico que foca nos adversários aponta 2005 como um pico para as 3 organizações: Força Sindical, que é um sindicato mais alinhado à direita, Partido Socialismo e Liberdade (PSOL) e Partido Socialista dos Trabalhadores Unificados (PSTU), que são partidos de oposição de esquerda ao governo. (MELO; TATAGIBA, 2017, p. 8)

Destarte, o decênio de 2004 a 2014 apresentou-se sob a moldura da bifocalidade. A ascensão do Partido dos Trabalhadores ao governo federal estabeleceu um novo repertório de interação com o MST, trazendo para a cena um novo padrão de negociação, ainda que a rotinização dos protestos não necessariamente tenha conseguido reduzir os conflitos fundiários no cenário nacional. Com relação à nossa pesquisa, o estudo desse período impulsionou a reflexão sobre até que ponto a institucionalização do MST significou a contenção ou a perda da sua autonomia.

Como um paradigma para a análise da terceira década, fomos guiados pela existência de uma matéria que denominamos de "matéria-tronco", publicada em 24 de maio de 2009. Nesta, o sociólogo José de Souza Martins, especialista em estudos rurais, aponta que à revelia da presença de um desencontro profundo entre as motivações imediatas do sujeito sem-terra e a ação dos movimentos sociais, a luta agrária tem resistido à ordem latifundiária. Além de problematizar as multiplicidades de organizações voltadas para a luta pela terra, 0 referido sociólogo questiona a ausência no discurso dos mediadores interpretativos, da crítica à questão da renda fundiária e da reforma agrária de mercado.

Nesse sentido, a base de dados compilada pelos softwares fez-se eloquente. $O$ repertório de interação entre a arena estatal e o MST tornou-se aparente por meio de categorias discursivas como "aproximação", "negociação" e "aliança". Termos como "gestão" e "políticas públicas" tornaram-se cada vez mais presentes no discurso do MST e sobre o movimento. Com isso, a tipologia de protesto estabeleceu-se de outra forma. Ainda que as ocupações estivessem presentes, houve outra dinâmica emergindo, a exemplo de "audiências públicas" e "barulhaços". 


\section{CONCLUSÃO}

Por meio da codificação das matérias utilizando os softwares Sphinx e Atlas.ti foi possível cotejar as mudanças discursivas que permearam as três décadas de existência do MST. Os dados da fase exploratória apontam que houve mudanças profundas nas estratégias e nos discursos sobre as práticas organizacionais do movimento. As ocupações voltaram-se contra o agronegócio e não mais para o latifúndio improdutivo, sendo que as categorias "multinacionais", "conglomerados industriais" e "invasão de laboratórios" aparecem como ações mais frequentes. A luta contra a propriedade privada da terra, que, a princípio, era a base de luta desse movimento, transforma-se na luta por uma reforma agrária possível e negociada no interior das estruturas burocráticas do Estado, com líderes do MST ocupando, de forma legítima, cargos no executivo e no legislativo. Observamos, inclusive, que o discurso se ampliou para outras temáticas, como o discurso ambientalista e o produtivista, no sentido de inserir o camponês na agricultura de mercado, não apenas defendendo as bases camponesas da economia moral do grupo doméstico familístico, voltado para a ética camponesa da economia solidária. (CHAYANOV, 1974)

Em função dessa inflexão observada nos 30 anos de ação do MST, relatados pela mídia nacional, tornou-se fundamental para o nosso trabalho analítico pensar quais conceitos se tornaram necessários para operacionalizar a análise à luz da hipótese inicial, como o processo de burocratização e transformação interna das estruturas organizacionais do movimento.

Para além do uso dos softwares, foi necessário salientar que o material coletado a partir da codificação deveria se relacionar com as hipóteses teóricas inicialmente escolhidas e posteriormente refinadas. Os dados, por serem extensos, demandaram o uso de tecnologias sofisticadas para serem tratados e nos ajudaram a traçar novos percursos analíticos trazendo à tona diferentes perspectivas da realidade social analisada, levando-nos a concordar ou discordar dos objetivos originalmente lançados pela questão investigativa preliminar da pesquisa. $O$ ponto positivo da utilização dos programas é a possibilidade de perceber variáveis que se associam aos conceitos teóricos da pesquisa, justamente por nos ajudar a visualizar de forma detalhada um lapso temporal sociologicamente dilatado. No caso dessa pesquisa, os 30 anos da história do MST mostraram-se heterogêneos e hermeneuticamente ricos na medida em que, ao serem cotejados de forma mais refinada e apurada por meio da utilização 
dos softwares já mencionados, alcançamos uma profundidade qualitativa e quantitativa expressiva, uma vez que a metodologia utilizada nos possibilitou analisar um pouco mais de 50\% de um volume de 8264 arquivos com matérias jornalísticas, gráficos e imagens.

Em resumo, na nossa pesquisa sobre a mídia impressa e o MST, entre os anos de 1984 a 2014, foi possível constatar a inegável contribuição dos CAQDAS para o ordenamento, a organização e o refinamento dos dados na geração de relatórios, assim como realizar novas abordagens analíticas sobre um tema grandemente explorado na pesquisa sociológica sobre os movimentos sociais, as mídias e os estudos rurais. Verificamos, assim, que os CAQDAS aumentaram as possibilidades da pesquisa com imensos volumes de dados estruturados e não estruturados, além de oferecerem a possibilidade de análise de um número maior de variáveis para a investigação de uma determinada realidade social - que, neste caso, implica compreender as mudanças e as afinidades eletivas da história recente do Movimento dos Trabalhadores Sem Terra inserida no complexo cenário da estrutura fundiária brasileira.

\section{REFERÊNCIAS}

BABBIE, E. Métodos de pesquisa de survey. Belo Horizonte: Ed. UFMG, 1999.

BARDIN, L. Análise de conteúdo. 70. ed. Lisboa: LD, 2009.

BARRANCO, J; WISLER, D. Validity and Systematicity of Newspaper Data in Event Analysis. European Sociological Review, Oxford, v. 15, n. 3, p. 301-302, 1999.

BASIT, T. Manual or Eletronic? The Role of Coding in Qualitative Data Analysis. Educational Research, Oxfordshire, v. 45, n. 2, p. 143-154, 2003. Disponível em: http:// www.tandf.co.uk/journals. Acesso em: 23 jan. 2018.

BOURDIEU, P. Introdução a uma sociologia reflexiva: em o poder simbólico. 5. ed. Rio de Janeiro: Bertrand Brasil, 2002.

CHAYANOV, A. V. La organizacion de la unidad economica campesina. Buenos Aires: Nova Vision, 1974.

COMPARATO, B. K. A ação política do MST. São Paulo em Perspectiva, São Paulo, n. 15, p. $105-118,2001$. 
FRANZOSI, R. The Press as a Source of Socio-historical Data: Issues in the Methodology of Data Collection from Newspapers. Historical Methods, Washington, v. 20, p. 5-16, 1987.

FRASER, N.; HONNETH, A. ¿Redistribuición o reconocimiento?: un debate políticofilosófico. Madrid: Morata, 2006.

GIBBS, G. Análise de dados qualitativos. Porto Alegre: Artmed, 2009.

GOHN, M. G. M. Novas teorias dos movimentos sociais. São Paulo: Loyola, 2010.

IVO, A. B. L. La destitución de lo social: Estado, gobierno y politicas sociales. Estudios Sociológicos, México, v. 23, n. 68, p. 347-374, 2005.

LAGE, M.; GODOY, A. S. O uso do computador na análise de dados qualitativos: questões emergentes. RAM - Revista de administração Mackenzie, São Paulo, v. 9, n. 4, p. $75-98,2008$.

LAGE, M. C. Os softwares tipo CAQDAS e a sua contribuição para a pesquisa qualitativa em educação. Revista ETD - Educação Temática Digital, Campinas, v. 12, n. 2, p. 42-58, 2011.

LEWINS, A.; SILVER, C. Choosing a CAQDAS Package. Guildford: University of Surrey, 2009.

LUPTON, D. Digital Sociology. London: Routledge, 2015.

MELO, L. P.; TATAGIBA, L. F. Impactos do "Lulismo" nos padrões de protestos do Brasil (2003-2010): uma abordagem exploratória. In: CONGRESSO LATINO-AMERICANO DE CIÊNCIA POLÍTICA (ALACIP), 9., 2017, Montevidéu. Anais [...]. Montevidéu: ALACIP, 2017.

MUELLER, C. Media measurement models of protest event data. Mobilization, San Diego, v. 2, p. 165-184, 1997.

MYERS, D. J.; CANIGLIA, B. S. All the Rioting That's Fit to Print: Selection Effects in National Newspaper Coverage of Civil Disorders,1968-1969. American Sociological Review, Menasha, v. 69, p. 519-543, 2004.

NASCIMENTO, L. F. Digital Sociology de Deborah Lupton. Caderno CRH, Salvador, v. 28, n. 75, p. $671-673,2015$.

NASCIMENTO, L. F. A sociologia digital: um desafio para o século XXI. Sociologias, Porto Alegre, v. 18, n. 41, p. 216-241, 2016.

OLIVER, P.; MANEY, G. Political Processes and Local Newspaper Coverage of Protest Events: From Selection Bias to Triadic Interactions. American Journal of Sociology, Chicago, v. 106, p. 463-505, 2000.

RIPLEY, B. et al. D.R Core Team. R: A Language and Environment for Statistical Computing. Vienna: R Foundation for Statistical Computing, 2013. 
SIMÕES, S.; PEREIRA, M. A. A arte e a ciência de fazer perguntas. In: AGUIAR, N. (org.). Desigualdades sociais, redes de sociabilidade e participação politica. Belo Horizonte: Ed. UFMG, 2007. p. 241-261.

STRAUSS, A.; CORBIN, J. Pesquisa qualitativa: técnicas e procedimentos para o desenvolvimento de teoria fundamentada. Porto Alegre: Artmed, 2008.

WEBER, M. Economia e sociedade. Brasília: Universidade de Brasília, 1991. 